\title{
Design, synthesis and molecular docking of novel triazole derivatives as potential $\mathrm{CoV}$ helicase inhibitors
}

\author{
NASHWA HAFEZ ZAHER ${ }^{1, *}$ \\ MOHAMMED ISMAIL MOSTAFA ${ }^{2}$ \\ ABDULLAH YOUSEF ALTAHER ${ }^{3}$ \\ ${ }^{1}$ Radiation Drug Research Department \\ National Center for Radiation Research \\ and Technology (NCRRT) \\ Egyptian Atomic Energy Authority \\ (EAEA), Cairo, Egypt \\ ${ }^{2}$ Department of Pharmacology \\ College of Veterinary Medicine, Cairo \\ University, Gizah, Egypt \\ ${ }^{3}$ Department of Physiology, Biochemistry \\ and Pharmacology, College of Veterinary \\ Medicine, King Faisal University \\ Alhasa, Kingdom of Saudi Arabia
}

Accepted August 8, 2019

Published online September 23, 2019

\begin{abstract}
Middle East respiratory syndrome coronavirus (MERS-CoV) had emerged and spread because of the worldwide travel and inefficient healthcare provided for the infected patients in several countries. Herein we investigated the anti-MERS-CoV activity of newly synthesized sixteen halogenated triazole compounds through the inhibition of helicase activity using the FRET assay. All new compounds underwent justification for their target structures via microanalytical and spectral data. SAR studies were performed. Biological results revealed that the most potent compounds were 4-(cyclopent-1-en-3-ylamino)-5-(2-(4-iodophenyl)hydrazinyl)-4H-1,2,4-triazole-3-thiol (16) and 4-(cyclopent-1-en-3-ylamino)-5-[2-(4-chlorophenyl)hydrazinyl]-4H-1,2,4-triazole-3-thiol (12). In silico molecular docking of the most potent compounds was performed to the active binding site of MERS-CoV helicase nsp13. Molecular docking results are in agreement with experimental findings.
\end{abstract}

Keywords: triazole derivatives, anti-MERS-CoV activity, MERS-CoV helicase, docking

Coronaviruses represent substantial human pathogens that have risen multiple times from zoonotic reservoirs over the past few centuries (1). Middle East respiratory syndrome coronavirus (MERS-CoV) is a recently discovered coronavirus. It is considered a threat to global public health, causing severe pneumonia in patients of the Middle East, with $40 \%$ fatality rate (2). It was first isolated in September 2012 (3). Both severe acute respiratory syndrome coronavirus (SARS-CoV) and MERS-CoV belong to the Coronaviridae family, which are enveloped, are positive-stranded RNA viruses with approximately 30,000 nucleotides (4). MERS-CoV displays symptoms like human severe acute respiratory syndrome (SARS) infections, consisting of sickness, rigors, weaknesses and high fevers, signs like influenza infection, but later develops to atypical pneumonia in most of the cases and commonly fatal acute respiratory illness (5).

The fatality rate in patients infected with MERS-CoV, estimated to be $43 \%$ as reported by World Health Organization (WHO), is higher than that of SARS (estimated $15 \%$ ) and is

\footnotetext{
* Correspondence; e-mail address: nashwazah@hotmail.com
} 
strongly age- and sex-dependent (6). Recent transmission in healthcare settings was obvious due to the contact and use of facilities by non-diagnosed infected patients. It has been reported by WHO that the majority, namely $83 \%$ of the cases, were identified in Saudi Arabia (7). However, many antiviral agents have been identified to inhibit MERS in vitro, though there are currently no approved antiviral agents or vaccines available to tackle any potential MERS outbreaks (8). Stockman and co-workers (9) reported that the present antiviral agents had minimal beneficial effects and had sometimes even worsened the symptoms of SARS patients. There are no specific treatments for MERS, therefore there is a need to develop effective anti-SARS agents for any SARS or MERS outbreak in the future. Progress in the drug development combating MERS is based on different molecular targets, one of which is based on coronavirus helicase (10).

Helicases are proteins that catalyze the separation of duplex oligonucleotides into single strands exploiting the derived energy from ATP hydrolysis (11).

The MERS-CoV helicase non-structural protein 13 (M-nsp13) is a critical component for viral replication and is presently viewed as a possible drug target for potential coronavirus chemical inhibitors (12). Its substrates are double-stranded RNAs (dsRNA). The main mode of action is the unwinding of a substrate in a process depending mainly on ATP gradient in a 5'-to- $3^{\prime}$ direction. Length of the $5^{\prime}$ loading strand of the partially duplex RNA substrate is another factor playing a crucial role affecting the efficiency of the unwinding reaction (13). Because of all these helicase functions, MERS helicase is considered a powerful antiviral target.

Triazoles are versatile heterocyclic moieties with a broad spectrum of pharmacological activities (14). He and coworkers (15) reported that triazole derivatives had shown potency as antiviral agents against H1N1influenza virus. The 1,2,4-triazole derivative was found to show the best activity against influenza B among all of compounds evaluated in a study by Zhao and Aisa (16). A limited number of possible inhibitors of nsp13 have been explored (17). SSYA10-001 is a 1,2,4-triazole derivative which was reported as an nsp13 non-competitive inhibitor through the blockage of SARS and MERS-CoV replication. It was postulated that SSYA10-001 binding pocket of SARS-CoV nsp13 is preserved among different coronavirus helicases, indicating the discovery of broad-spectrum coronavirus inhibitors. SSYA10-001was reported as potential effective inhibitor of viral replication in MERS-CoV replicon (Fig. 1) (18).

All the above mentioned prompted us to design and synthesize new 1,2,4-triazole derivatives in order to be screened as helicase inhibitors that simply prevent the replication of MERS-CoV.

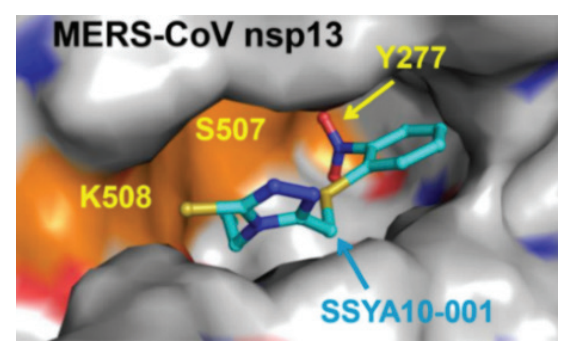

Fig. 1. SSYA10-001 docking into the inhibitor-binding pocket of MERS-CoV (18). 
N. H. Zaher et al:: Design, synthesis and molecular docking of novel triazole derivatives as potential CoV helicase inhibitors, Acta Pharm. 70 (2020) 145-159.

\section{EXPERIMENTAL}

\section{Reagents and instruments}

A Stuart melting point apparatus (Stuart Scientific, UK) was used for the recording of uncorrected melting points in open capillary tubes. An FT-IR Shimadzu spectrometer (Shimadzu, Japan) was used for recording IR spectra. A Bruker AC-500 Ultra Shield NMR spectrometer (Bruker, Switzerland) was used for recording ${ }^{1} \mathrm{H}$ NMR and ${ }^{13} \mathrm{C}$ NMR spectra, at $500 \mathrm{MHz}$. Trimethylsilane was used as an internal standard. Deuterated dimethylsulfoxide was the solvent of choice. An HP Model MS-5988 (Hewlett Packard, USA) was used for recording mass spectra. A Carlo Erba 1108 Elemental Analyzer (W. C. Heraeus GmbH, Germany) was used for providing microanalyses. All elemental analyse values were within $\pm 0.4 \%$ of the theoretical value.

Starting triazole and all reagents used were of analytical grade and were purchased from Sigma (USA).

\section{Syntheses}

The solvent-free reaction of arylamines constitutes one of the most widely used methods for the preparation of different amine derivatives (19).

General procedure for 4-amino-5-(substituted phenyl hydrazine)-4H-1,2,4-triazole-3-thiols 1-8. - A mixture of 4-amino-5-hydrazino-4H-1,2,4-triazole-3-thiol (1 g, $0.007 \mathrm{~mol})$ and different reagents $(0.007 \mathrm{~mol})$ (1,2-difluorobenzene $(0.8 \mathrm{~g})$, 1,4-difluorobenzene $(0.8 \mathrm{~g}), 1,2$-dichlorobenzene (1 g), 1,4-dichlorobenzene (1 g), 1,2-dibromobenzene (1.65 g), 1,4-dibromobenzene (1.65 g), 1,2-diiodobenzene ( $2.3 \mathrm{~g}$ ) or 1,4-diiodobenzene $(2.3 \mathrm{~g})$ was heated at $150{ }^{\circ} \mathrm{C}$ for $5 \mathrm{~min}$ with stirring. The formed residue was dried and recrystallized from ethanol to give compounds 1-8, resp.

The obtained compounds were: 4-amino-5-(2-fluorophenyl hydrazine)-4H-1,2,4-triazole3-thiol (1), 4-amino-5-(4-fluorophenyl hydrazine)-4H-1,2,4-triazole-3-thiol (2), 4-amino-5-(2chlorophenyl hydrazine)-4H-1,2,4-triazole-3-thiol (3), 4-amino-5-(4-chlorophenyl hydrazine)4H-1,2,4-triazole-3-thiol (4), 4-amino-5-(2-bromophenyl hydrazine)-4H-1,2,4-triazole-3-thiol (5), 4-amino-5-(4-bromophenyl hydrazine)-4H-1,2,4-triazole-3-thiol (6), 4-amino-5-(2-iodophenyl hydrazine)-4H-1,2,4-triazole-3-thiol (7), 4-amino-5-(4-iodophenyl hydrazine)-4H-1,2,4-triazole-3-thiol (8).

General procedure for 4-(cyclopent-1-en-3-ylamino)-5-[2-(substituted phenyl) hydrazinyl]-4H1,2,4-triazole-3-thiols $\mathbf{9 - 1 6}$ - Each of compounds $\mathbf{1 - 8}$ reacted with an equimolar quantity of 3-chlorocyclopent-1-ene under fusion at $150^{\circ} \mathrm{C}$ for $5 \mathrm{~min}$ with stirring. The formed residue was dried and recrystallized from ethanol to give compounds 9-16, resp.

The obtained compounds were: 4-(cyclopent-1-en-3-ylamino)-5-[2-(2-fluorophenyl) hydrazinyl]-4H-1,2,4-triazole-3-thiol (9), 4-(cyclopent-1-en-3-ylamino)-5-[2-(4-fluorophenyl) hydrazinyl]-4H-1,2,4-triazole-3-thiol (10), 4-(cyclopent-1-en-3-ylamino)-5-[2-(2-chlorophenyl) hydrazinyl]-4H-1,2,4-triazole-3-thiol (11), 4-(cyclopent-1-en-3-ylamino)-5-[2-(4-chlorophenyl hydrazinyl]-4H-1,2,4-triazole-3-thiol (12), 4-(cyclopent-1-en-3-ylamino)-5-[2-(2-bromophenyl)hydrazinyl]-4H-1,2,4-triazole-3-thiol (13), 4-(cyclopent-1-en-3-ylamino)-5-[2-(4-bromophenyl)hydrazinyl]-4H-1,2,4-triazole-3-thiol (14), 4-(cyclopent-1-en-3-ylamino)-5-[2-(2-iodophenyl)hydrazinyl]-4H-1,2,4-triazole-3-thiol (15), 4-(cyclopent-1-en-3-ylamino)-5-[2-(4-iodophenyl)hydrazinyl]-4H-1,2,4-triazole-3-thiol (16). 
N. H. Zaher et al:: Design, synthesis and molecular docking of novel triazole derivatives as potential CoV helicase inhibitors, Acta Pharm. 70 (2020) 145-159.

\section{Biological investigations}

M-nsp13 helicase preparation. - Antiviral activity was tested using a helicase specific assay in which a purified M-nsp13 cloned helicase domain was used. GenBank accession no. JX869059.2. (Bi Biotech, New Delhi, India). PCR was used for the amplification of the DnaB helicase from E. coli genomic, according to the literature procedure (20). PET28a conjugated plasmid was used for the expression to which a purified PCR product was translocated to. Conjugated M-nsp13-pET28a was cultivated overnight in LB culture for expression. M-nsp13 was obtained by SDS-polyacrylamide gel electrophoresis (PAGE). Separated protein was stored at $-20^{\circ} \mathrm{C}$ to be used in ATPase assay using standard method (21), where sonication and centrifugation were carried out to obtain the insoluble fraction. Purification was accomplished by washing with $50 \mathrm{mmol} \mathrm{L}^{-1} \mathrm{Tris}-\mathrm{HCl}(\mathrm{pH}$ 7.4). The obtained protein was then dissolved in a mixture of $6 \mathrm{~mol} \mathrm{~L}^{-1} \mathrm{CuCl}_{2}, 50 \mathrm{mmol} \mathrm{L}^{-1}$ Tris $\mathrm{HCl}$ (pH 7.4) and $20 \mathrm{mmol} \mathrm{L}^{-1}$ imidazole. Protein renaturation was done by rapid vortexing of the soluble protein into a mixture of Tris $\mathrm{HCl}(\mathrm{pH} 6.8), 5 \mathrm{mmol} \mathrm{L}^{-1} \mathrm{MgCl}_{2}, 20 \%$ glycerol/1 $\%$ Triton, $10 \mathrm{mmol} \mathrm{L}^{-1} \beta$-mercaptoethanol, on ice. The protein was eluted with $100 \mathrm{mmol}$ $\mathrm{L}^{-1}$ Tris $\mathrm{pH}$ 8.0, $150 \mathrm{mmol} \mathrm{L}^{-1} \mathrm{NaCl}, 10 \mathrm{mmol} \mathrm{L}^{-1}$ desthiobiotin, $0.1 \%$ Triton X-100, $5 \mathrm{mmol}$ $\mathrm{L}^{-1} \beta$-mercaptoethanol and $5 \%$ glycerol, then the protein was stored at $-20{ }^{\circ} \mathrm{C}$.

ATPase assay. - Measuring the ATPase assay was carried through phosphomolybdate-Malachite green assay $5 \mathrm{~min}$ reaction. The reaction mixture consisted of $50 \mathrm{mmol} \mathrm{L}^{-1}$ Tris$-\mathrm{HCl}(\mathrm{pH} 6.8), 5 \mathrm{mmol} \mathrm{L}^{-1} \mathrm{MgCl}_{2}, 0.1 \mathrm{mg} \mathrm{mL}^{-1} \mathrm{BSA}$ and $3.2 \mathrm{ng} \mathrm{M}$-nsp13 helicase, in $50 \mu \mathrm{L}$.

The newly synthesized derivatives 1-16 were evaluated for their ATPase inhibitory activity in different concentrations. Fitting of the data was done by using the modified form of the equation first given by Porter (21):

$$
A([\mathrm{~L}])=1-\left\{\left(\Delta A_{\infty}[\mathrm{L}]\right) /\left(I C_{50}+[\mathrm{L}]\right)\right\}
$$

where $A([\mathrm{~L}])$ is the ATPase activity at a ligand concentration [L] $\left(\mathrm{L}-\mathrm{MgCl}_{2}\right)$, and $\Delta A_{\infty}$ is the maximal decrease in ATPase activity at an infinite concentration of $\mathrm{L}$. $I C_{50}$ was extrapolated from the curve for each compound tested.

FRET-based helicase assays. - The convenient method reported by Boguszewska and coworkers (22), was used for testing both helicase and ATPase activity colorimetrically and fluorometrically through fluorescence resonance energy transfer (FRET). The amount of phosphate released during the reaction is reduced via present ATPase inhibitors and so the measured absorbance is reduced. This protocol relies on the cloning of M-nsp 13. Expression was done by utilizing the following primer forward: 5'BamHI-nsp13-CGGGATCCTG CTGTAGGCTCTTGTGTTG-3' and 3'EagI-nsp13-ATGCGGCCGCTATTGCAGCTTGTAG TTGGTAAAGCTC- $3^{\prime}$ as the reverse one. In brief, annealing was done by heating a mixture of the two primers at a ratio 1:1.2 of forward:reverse primers to $90^{\circ} \mathrm{C}$, then cooling over one hour to $40^{\circ} \mathrm{C}$. Newly synthesized derivatives $\mathbf{1 - 1 6}$ were then added to the reaction mixture in varying concentrations. Released phosphate is quantified after $5 \mathrm{~min}$ in the colorimetric assay. To mimic the nucleic acid-stimulated NTPase activity of the m-nsp13 helicase, Oligo-dT24 was incorporated in the assay. The average change of fluorescence at excitation $550 \mathrm{~nm}$ and emission $570 \mathrm{~nm}$ was reported in triplicate, as an indicator of the extent of duplex unwinding. Data were fitted using the standard equation and $I C_{50}$ for each derivative was estimated. 


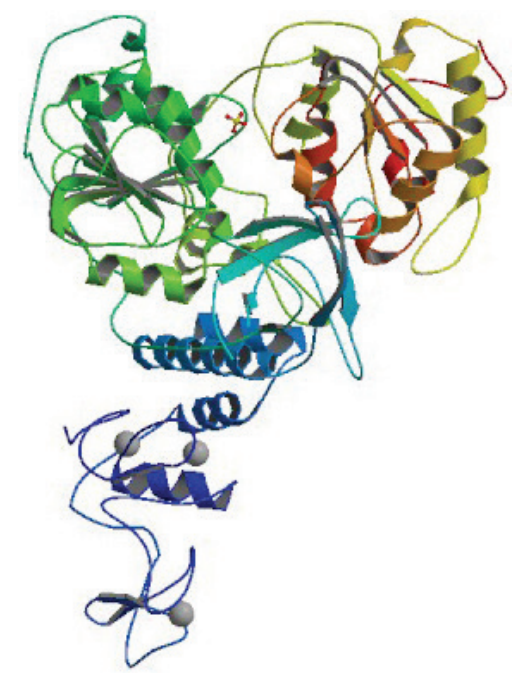

Fig. 2. Crystal structure of Middle East respiratory syndrome coronavirus helicase (MERS-CoV nsp13) (PDB 5WWP).

Molecular modeling. - Docking investigation was carried using the molecular operating environment (MOE 2008.10) (23) on the basis of high-resolution crystal structures of MERSCoV nsp13 helicase: Protein Data Bank (PDB), 5WWP (Fig. 2). Target protein and compounds, synthesized as ligands, were energy-minimized. Removal of water molecules and the addition of hydrogen atoms were performed. Assignment of amino acid residues' protonation, using the Protonate3D algorithm with 30 total runs was done. Most potent newly synthesized compounds 4-(cyclopent-1-en-3-ylamino)-5- [2-(4-iodophenyl) hydrazinyl]-4H-1,2,4-triazole-3-thiol (16) and 4-(cyclopent-1-en-3-ylamino)-5-[2-(4-chlorophenyl) hydrazinyl]-4H-1,2,4-triazole-3-thiol (12), were docked into MERS-CoV nsp13 helicase site. Interactions with amino acid residues were identified within the active binding site.

\section{RESULTS AND DISCUSSION}

\section{Chemistry}

The starting 4-amino-5-hydrazino-4H-1,2,4-triazole-3-thiol has a highly reactive nucleophilic character with three nucleophilic active centers that promote different substitution reactions. Sixteen new compounds were obtained in very good to excellent yields and screened against MERS CoV-helicase activity. The synthetic pathways adopted for the synthesis of the target 1,2,4-triazole-based compounds 1-16 proceeded via simple, straight forward and solvent-free reactions which are outlined in Scheme 1.

In a structure-activity relationship (SAR) discussion, SSYA10-001 was taken as a lead compound and main features required for inhibiting MERS-CoV nsp13 (Fig. 1) were observed (Fig. 3). 


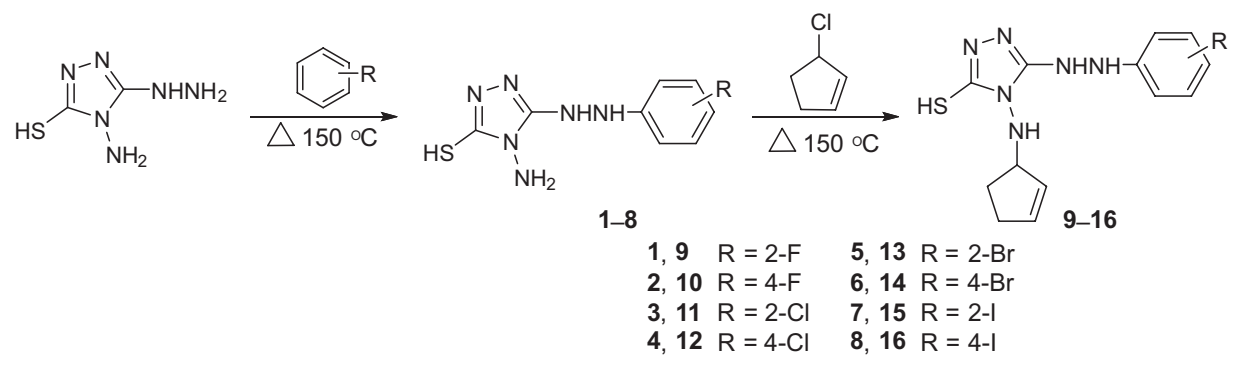

Scheme 1

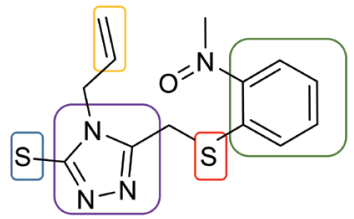

SSYA10-001

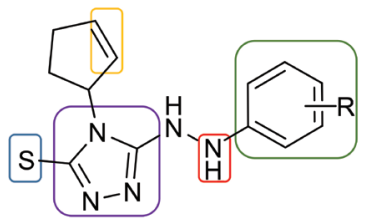

4-(Cyclopent-1-en-3-ylamino)-5-(2-(halophenyl)hydrazinyl)-4H-1,2,4-triazole-3-thiol (9-16)

Fig. 3. Perceived main structural features between SSYA10-001 and compounds 9-16.

Structures of all obtained compounds were verified through $\mathrm{IR},{ }^{1} \mathrm{H}$ NMR, ${ }^{13} \mathrm{C}$ NMR, mass spectra and microanalytical data which were in conformity with the allocated structures (Tables I and II).

IR spectra of compounds $1-8$, displayed characteristic bands ascribed to aromatic $\mathrm{CH}$ groups at 3051-3059 $\mathrm{cm}^{-1}$ confirming the reaction of the starting triazole with phenyl reagents. ${ }^{1} \mathrm{H}$ NMR spectra for compounds $1-8$ revealed extra multiplet signals at $\delta 7.30-8.08$ ppm attributed to the introduced phenyl moiety. $\mathrm{NH}_{2}$ moiety was displayed at $\delta 2.38 \mathrm{ppm}$. $\mathrm{NH}$ signals were allocated at $\delta 4.79-4.83 \mathrm{ppm}$, exchangeable with $\mathrm{D}_{2} \mathrm{O}$, in addition to the signal at $\delta 4.30 \mathrm{ppm}$ allocated for $\mathrm{SH}$ group, exchangeable with $\mathrm{D}_{2} \mathrm{O} .{ }^{13} \mathrm{C}$ NMR spectrum of compound 1 revealed signals at $\delta 114,116.5,121,125,145$ and 155 ppm attributed to introduced ortho-substituted phenyl moiety. para-fluoro compound 2 displayed four signals at $\delta 114,116,147$ and $150 \mathrm{ppm}$, attributed to introduced para-substituted phenyl moiety. Moreover, mass spectra showed molecular ion peaks with $\mathrm{m} / \mathrm{z}$ at 240, 258, 303 and $348\left[\mathrm{M}^{+}\right]$ for compounds $1-2,3-4,5-6$ and 7-8, resp.

IR spectra of compounds 9-16, showed disappearance of the double intense peak of $\mathrm{NH}_{2}$, confirming a reaction at the specified position. Also, IR spectra showed absorption bands at 3053-3059 $\mathrm{cm}^{-1}$ assigned to the introduced aromatic moiety. In addition, appearance of bands in the range $2888-2953 \mathrm{~cm}^{-1}$, allocated for aliphatic hydrocarbons of cyclopentenyl ring, confirmed reaction at the specified position. ${ }^{1} \mathrm{H}$ NMR spectra for target compounds 9-16 displayed extra multiplet signals at $\delta 3.84,4.24,4.40,4.60,4.80$ ppm, attributed to the introduced cyclopentene moiety. Additionally, there were multiplet signals at $\delta$ 6.90-8.01 ppm ascribed to ortho-substituted phenyl moieties in compounds 9, 11, 13 and 15. However, compounds 10, 12, 14 and $\mathbf{1 6}$ displayed doublet of doublet signals (6.69, $6.93 \mathrm{ppm}),(7.96,8.12 \mathrm{ppm}),(7.64,7.91 \mathrm{ppm})$ and $(7.96,8.24 \mathrm{ppm})$, resp., for four $\mathrm{CH}_{2}$ groups of para-substituted phenyl ring. Presence of $\mathrm{NH}$ and $\mathrm{SH}$ signals was confirmed at specified 
N. H. Zaher et al:: Design, synthesis and molecular docking of novel triazole derivatives as potential CoV helicase inhibitors, Acta Pharm. 70 (2020) 145-159.

Table I. Physicochemical and analytical data of the newly synthesized compounds 1-16

\begin{tabular}{|c|c|c|c|c|c|c|}
\hline \multirow{2}{*}{ Compd. } & \multirow{2}{*}{$\begin{array}{c}\text { Molecular } \\
\text { formula }\left(M_{\mathrm{r}}\right)\end{array}$} & \multirow{2}{*}{ M.p. $\left({ }^{\circ} \mathrm{C}\right)$} & \multirow{2}{*}{ Yield (\%) } & \multicolumn{3}{|c|}{ Analysis (calcd./found) (\%) } \\
\hline & & & & $\mathrm{C}$ & $\mathrm{H}$ & $\mathrm{N}$ \\
\hline \multirow{2}{*}{1} & $\mathrm{C}_{8} \mathrm{H}_{9} \mathrm{FN}_{6} \mathrm{~S}$ & \multirow{2}{*}{$>280$} & \multirow{2}{*}{87} & 39.99 & 3.78 & 34.98 \\
\hline & 240.26 & & & 40.11 & 3.65 & 35.10 \\
\hline \multirow{2}{*}{2} & $\mathrm{C}_{8} \mathrm{H}_{9} \mathrm{FN}_{6} \mathrm{~S}$ & \multirow{2}{*}{$>280$} & \multirow{2}{*}{86} & 39.99 & 3.78 & 34.98 \\
\hline & 240.26 & & & 40.18 & 3.64 & 35.01 \\
\hline \multirow{2}{*}{3} & $\mathrm{C}_{8} \mathrm{H}_{9} \mathrm{ClN}_{6} \mathrm{~S}$ & \multirow{2}{*}{$>280$} & \multirow{2}{*}{80} & 37.43 & 3.53 & 32.74 \\
\hline & 256.72 & & & 37.55 & 3.42 & 32.87 \\
\hline \multirow{2}{*}{4} & $\mathrm{C}_{8} \mathrm{H}_{9} \mathrm{ClN}_{6} \mathrm{~S}$ & \multirow{2}{*}{$>280$} & \multirow{2}{*}{82} & 37.43 & 3.53 & 32.74 \\
\hline & 256.72 & & & 37.59 & 3.40 & 32.88 \\
\hline \multirow{2}{*}{5} & $\mathrm{C}_{8} \mathrm{H}_{9} \mathrm{BrN}_{6} \mathrm{~S}$ & \multirow{2}{*}{$>280$} & \multirow{2}{*}{78} & 31.09 & 3.01 & 27.90 \\
\hline & 301.17 & & & 31.21 & 2.90 & 27.99 \\
\hline \multirow{2}{*}{6} & $\mathrm{C}_{8} \mathrm{H}_{9} \mathrm{BrN}_{6} \mathrm{~S}$ & \multirow{2}{*}{$>280$} & \multirow{2}{*}{77} & 31.09 & 3.01 & 27.90 \\
\hline & 301.17 & & & 31.20 & 2.95 & 28.06 \\
\hline \multirow{2}{*}{7} & $\mathrm{C}_{8} \mathrm{H}_{9} \mathrm{IN}_{6} \mathrm{~S}$ & \multirow{2}{*}{$>280$} & \multirow{2}{*}{89} & 27.60 & 2.61 & 24.14 \\
\hline & 348.97 & & & 27.77 & 2.57 & 24.23 \\
\hline \multirow{2}{*}{8} & $\mathrm{C}_{8} \mathrm{H}_{9} \mathrm{IN}_{6} \mathrm{~S}$ & \multirow{2}{*}{$>280$} & \multirow{2}{*}{90} & 27.60 & 2.61 & 24.14 \\
\hline & 348.97 & & & 27.81 & 2.50 & 24.32 \\
\hline 9 & $\mathrm{C}_{13} \mathrm{H}_{15} \mathrm{FN}_{6} \mathrm{~S}$ & $>280$ & 85 & 50.97 & 4.94 & 27.43 \\
\hline 9 & 306.36 & -200 & 05 & 51.01 & 4.77 & 27.59 \\
\hline 10 & $\mathrm{C}_{13} \mathrm{H}_{15} \mathrm{FN}_{6} \mathrm{~S}$ & $>280$ & 89 & 50.97 & 4.94 & 27.43 \\
\hline 10 & 306.36 & $>280$ & 89 & 51.05 & 4.79 & 27.52 \\
\hline 11 & $\mathrm{C}_{13} \mathrm{H}_{15} \mathrm{ClN}_{6} \mathrm{~S}$ & $>280$ & 90 & 48.37 & 4.68 & 26.03 \\
\hline 11 & 322.82 & $>\angle O 0$ & 90 & 48.39 & 4.71 & 26.12 \\
\hline 12 & $\mathrm{C}_{13} \mathrm{H}_{15} \mathrm{ClN}_{6} \mathrm{~S}$ & & 91 & 48.37 & 4.68 & 26.03 \\
\hline 12 & 322.82 & $>280$ & 91 & 48.39 & 4.71 & 26.12 \\
\hline 13 & $\mathrm{C}_{13} \mathrm{H}_{15} \mathrm{BrN}_{6} \mathrm{~S}$ & $>280$ & 82 & 42.51 & 4.12 & 22.88 \\
\hline 10 & 367.27 & -200 & 02 & 42.36 & 4.18 & 22.92 \\
\hline 14 & $\mathrm{C}_{13} \mathrm{H}_{15} \mathrm{BrN}_{6} \mathrm{~S}$ & & & 42.51 & 4.12 & 22.88 \\
\hline 14 & 367.27 & $>280$ & 83 & 42.69 & 4.10 & 22.93 \\
\hline 15 & $\mathrm{C}_{13} \mathrm{H}_{15} \mathrm{IN}_{6} \mathrm{~S}$ & $>280$ & 75 & 37.69 & 3.65 & 20.29 \\
\hline 10 & 414.27 & -200 & 10 & 37.66 & 3.62 & 20.22 \\
\hline 16 & $\mathrm{C}_{13} \mathrm{H}_{15} \mathrm{IN}_{6} \mathrm{~S}$ & $>280$ & & 37.69 & 3.65 & 20.29 \\
\hline 16 & 414.27 & $>280$ & 78 & 37.70 & 3.60 & 20.23 \\
\hline
\end{tabular}




\begin{tabular}{|c|c|c|c|c|c|c|c|}
\hline $\begin{array}{l}\frac{\varrho}{9} \\
\frac{N}{\equiv}\end{array}$ & 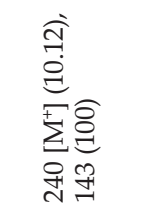 & 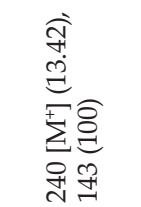 & 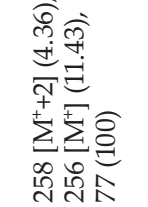 & 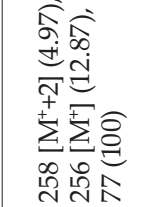 & 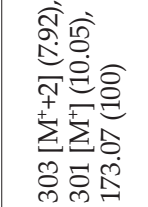 & 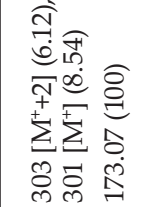 & 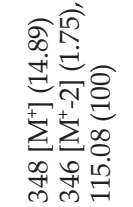 \\
\hline 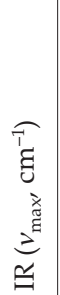 & 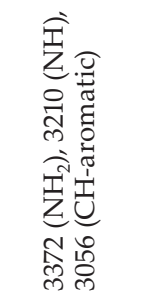 & 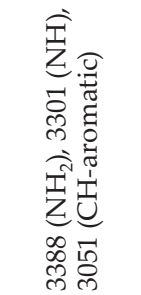 & 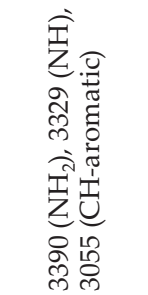 & 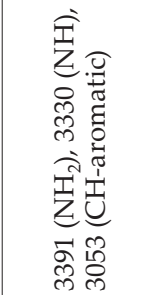 & 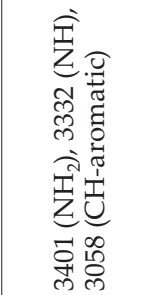 & 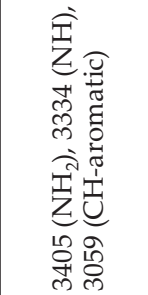 & 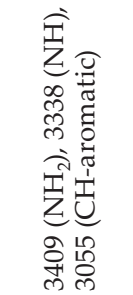 \\
\hline 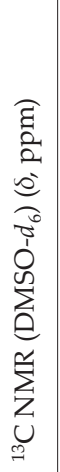 & 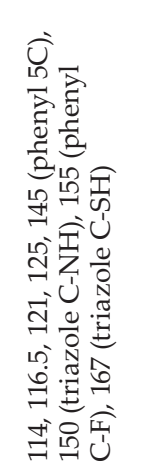 & 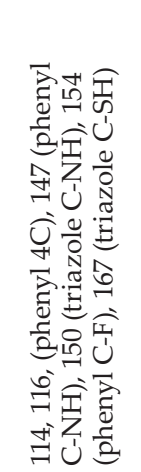 & 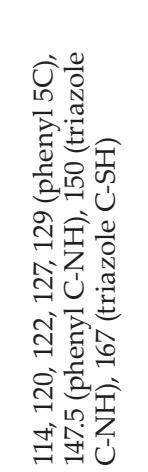 & 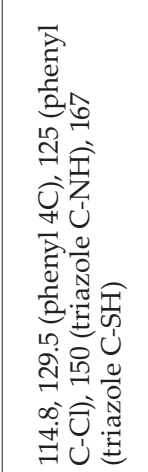 & 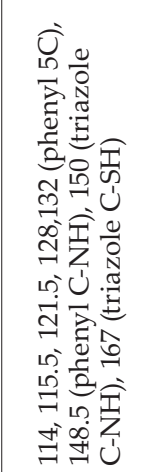 & 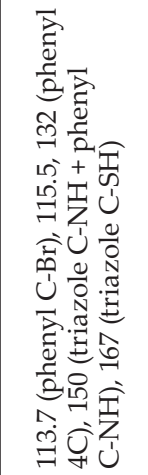 & 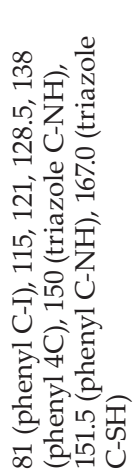 \\
\hline 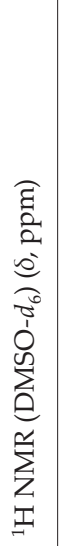 & 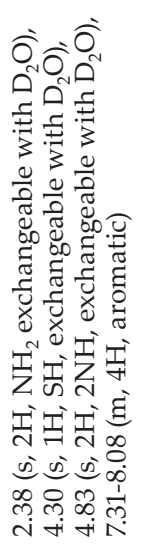 & 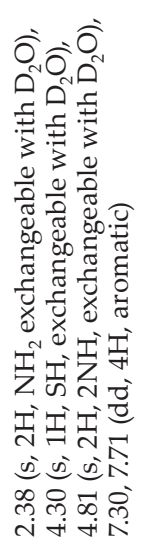 & 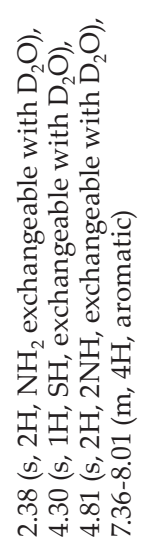 & 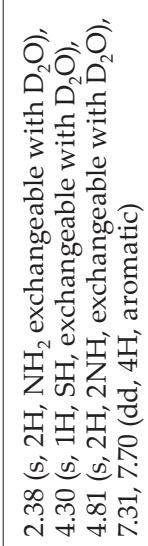 & 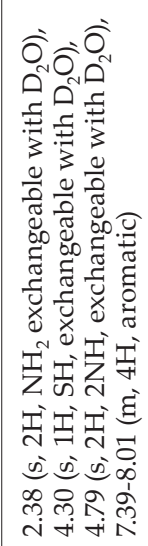 & 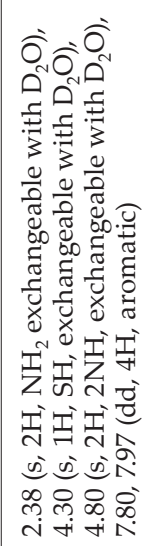 & 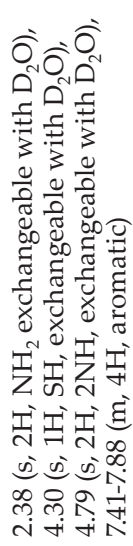 \\
\hline $\begin{array}{l}\overrightarrow{0} \\
\text { हे. } \\
\text { ठ் }\end{array}$ & 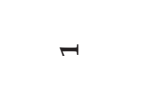 & $N$ & m & 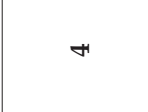 & in & 6 & \\
\hline
\end{tabular}




\begin{tabular}{|c|c|c|c|c|c|}
\hline ఠ & 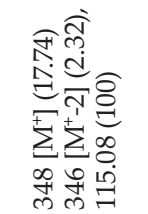 & 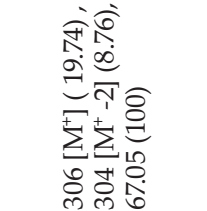 & 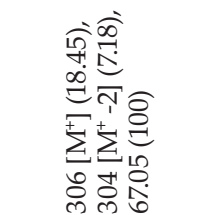 & 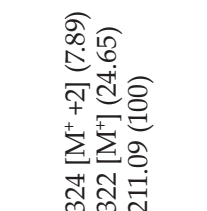 & 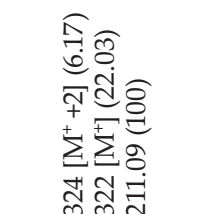 \\
\hline 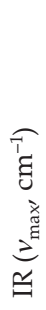 & 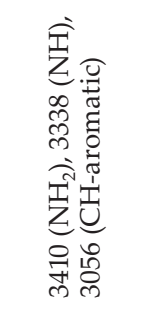 & 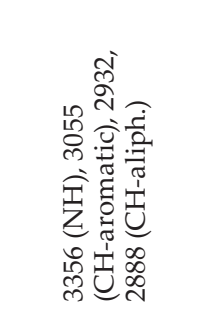 & 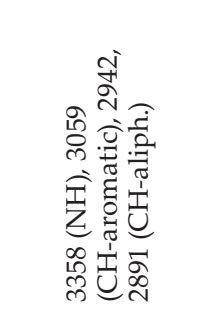 & 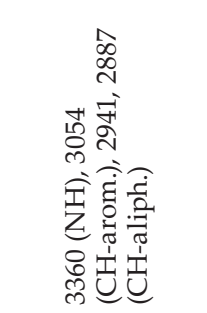 & 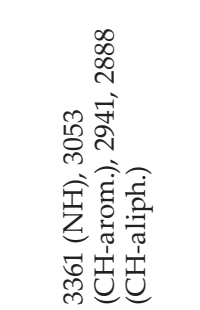 \\
\hline 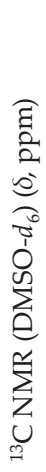 & 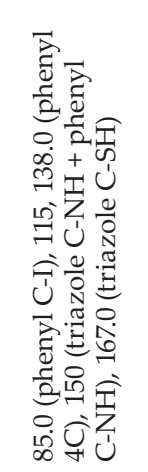 & 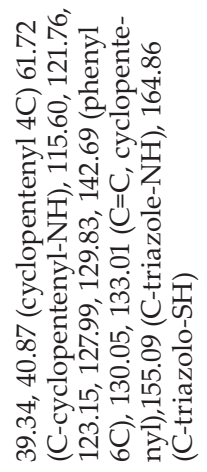 & 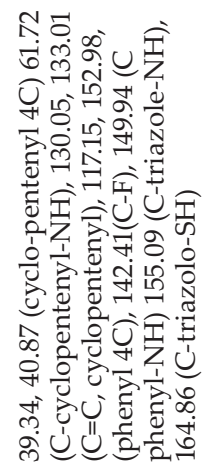 & 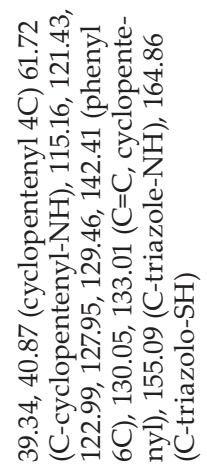 & 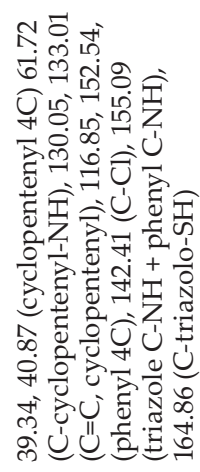 \\
\hline 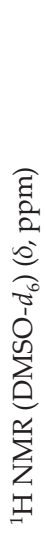 & 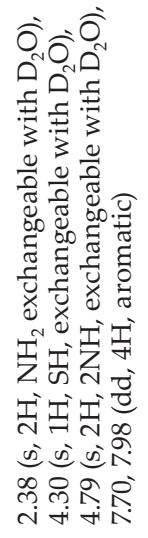 & 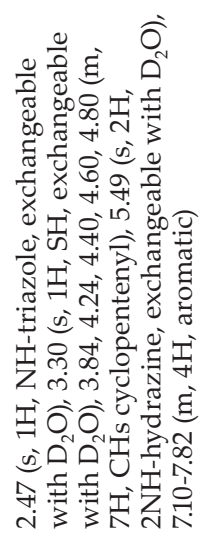 & 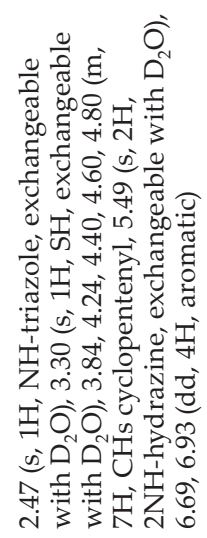 & 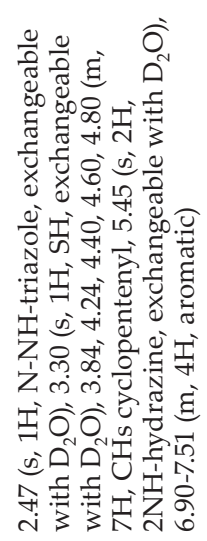 & 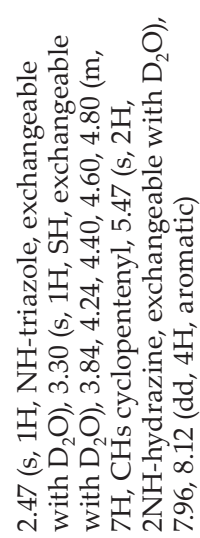 \\
\hline & $\infty$ & $\sigma$ & 이 & & $\pi$ \\
\hline
\end{tabular}




\begin{tabular}{|c|c|c|c|c|}
\hline & 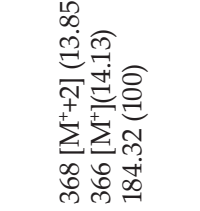 & 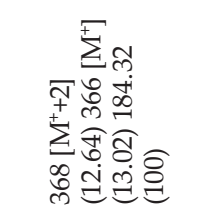 & 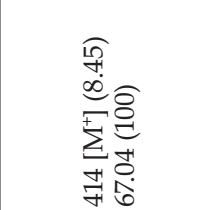 & 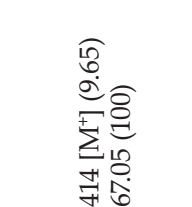 \\
\hline T્ & 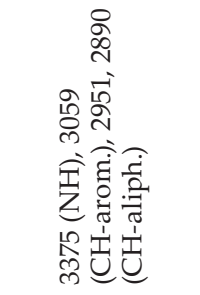 & 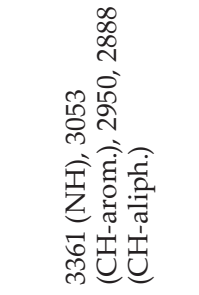 & 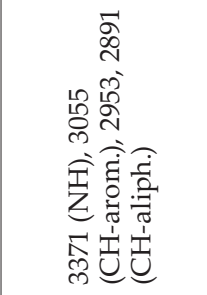 & 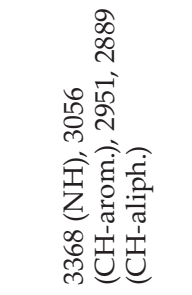 \\
\hline 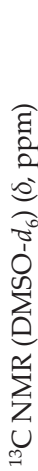 & 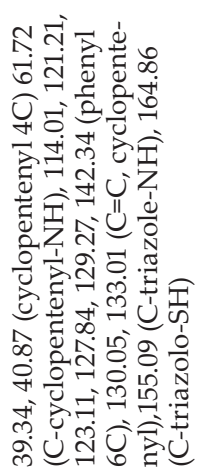 & 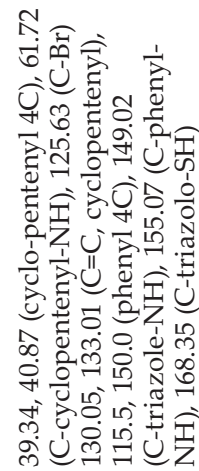 & 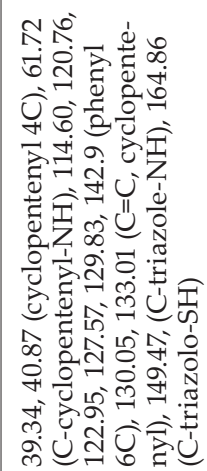 & 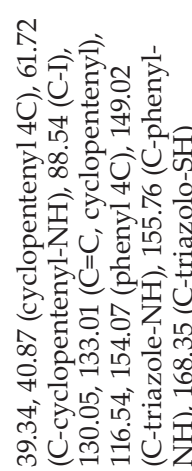 \\
\hline 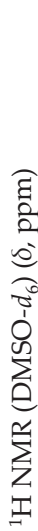 & 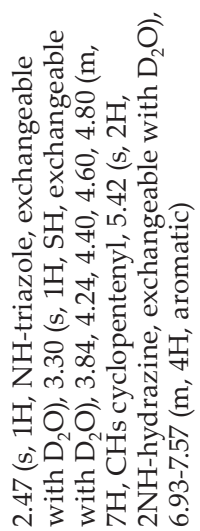 & 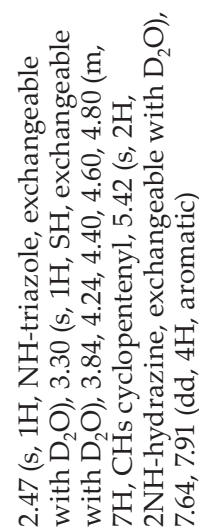 & 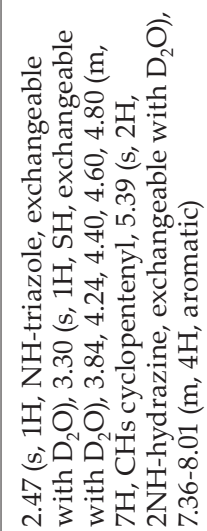 & 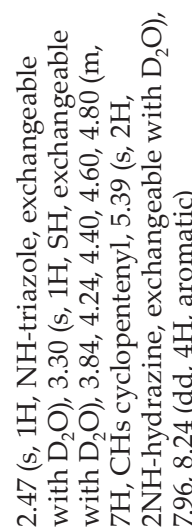 \\
\hline & $\approx$ & $\nexists$ & 늑 & $?$ \\
\hline
\end{tabular}


N. H. Zaher et al.: Design, synthesis and molecular docking of novel triazole derivatives as potential CoV helicase inhibitors, Acta Pharm. 70 (2020) 145-159.

positions, exchangeable with $\mathrm{D}_{2} \mathrm{O} .{ }^{13} \mathrm{C}$ NMR spectra for compounds 9-16 also revealed additional signals at $\delta 39.34$ and $40.87 \mathrm{ppm}$ attributed to the two carbons of cyclopentenyl. $\mathrm{C}-\mathrm{NH}$ of the cyclopentenyl was seen at $\delta 61.72 \mathrm{ppm}$, confirming its reaction at the specified position, whereas the $\mathrm{C}=\mathrm{C}$ of the cyclopentenyl appeared at $\delta 130.05$ and $133.01 \mathrm{ppm}$. Phenyl carbons' signals were seen at 114.01-154.07 ppm. Mass spectra were consistent with assumed structures where molecular ion peaks $\mathrm{m} / \mathrm{z}$ at $306,324,368$ and $414\left[\mathrm{M}^{+}\right]$, were seen for com-

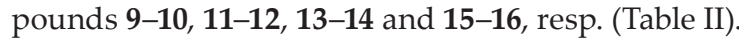

\section{Biological activity}

Till now there is no approved MERS CoV helicase inhibitors; however, some adamantine-derived bananins were reported as potent inhibitors of SARS CoV helicase with $I C_{50}$ values from 2.7 to more than $100 \mu \mathrm{mol} \mathrm{L}^{-1}(24)$.

Inhibition of helicase MERS-CoV enzymatic activity. - In this work, we have investigated the activity of newly halogenated 1,2,4 triazole derivatives (1-16) against MERS-CoV helicase. Current results showed that the starting compound 4-amino-5-hydrazino-4H-1,2,4-triazole-3-thiol inhibited the M-nsp 13 helicase and ATPase activity with $I C_{50}$ value of 12.4 and $8.9 \mu \mathrm{mol} \mathrm{L}^{-1}$, resp. (Table III). We herein showed that some halogenated 1,2,4-triazole derivatives revealed significant anti-MERS-CoV activity.

ATPase assays revealed that the presence of cyclopentenyl moiety is essential for good activity. Compounds 4-(cyclopent-1-en-3-ylamino)-5-[2-(4-iodophenyl) hydrazinyl]-4H-1,2,4triazole-3-thiol (16) and 4-(cyclopent-1-en-3-ylamino)-5- [2-(4-chlorophenyl) hydrazinyl]-4H-1,2,4-triazole-3-thiol (12) were the most effective MERS-CoV helicase inhibitors with ATPase $I C_{50}$ values of 0.47 and $0.51 \mu \mathrm{mol} \mathrm{L}{ }^{-1}$, resp. ortho-iodo derivative (15) with ATPase $I C_{50}$ of 2.73 $\mu \mathrm{mol} \mathrm{L}-1$ and ortho-chloro derivative (11) with ATPase $I C_{50}$ of $3.9 \mu \mathrm{mol} \mathrm{L}^{-1}$ were also moderate inhibitors. On the other hand, bromine derivatives 14 and 13 showed moderate inhibition with ATPase $I C_{50}$ of 4.0 and $5.3 \mu \mathrm{mol} \mathrm{L}-1$, resp. Compounds 9 and 10, bearing the fluorine atom, showed little if any inhibition, whereas compounds 1-8 showed no inhibition at all (Table III). Mostly, the measured helicase activity inhibition for each compound was lower than the corresponding ATPase inhibition activity.

\section{Molecular modeling}

The major step to initiate drug design is to identify and select the most appropriate drug target. The target protein for this study is M-nsp 13 helicase protein (Fig. 2). Docking of the most potent compounds, 4-(cyclopent-1-en-3-ylamino)-5-[2-(4-iodophenyl) hydrazinyl]-4H-1,2,4-triazole-3-thiol (16) and 4-(cyclopent-1-en-3-ylamino)-5-[2-(4-chlorophenyl) hydrazinyl]-4H-1,2,4-triazole-3-thiol (12), was performed in the active binding site of 5WWP. Thirty conformations for each browser molecule were saved. Finally, the best conformation with best binding interactions along with the lowest binding energy was selected (Fig. 4).

Binding of compounds in 5WWP active site could be attributed to the incorporation of a nitrogen atom and aromatic rings, which is generally common to other inhibitors as SSYA-10. However, the difference in their substitution pattern resulted in the difference in their binding affinity. Molecular modeling result confirms the crucial role of the following amino acids in the active pocket: Tyr 159, Tyr 7, Tyr 171 and Arg 163. It was obvious that the binding interaction with Tyr 159 is essential for activity. 
N. H. Zaher et al.: Design, synthesis and molecular docking of novel triazole derivatives as potential CoV helicase inhibitors, Acta Pharm. 70 (2020) 145-159.

Table III. $\mathrm{IC}_{50}$ values of compounds 1-16 for the inhibition of both ATPase and helicase activities of MERS-CoV

\begin{tabular}{|c|c|c|}
\hline \multirow[b]{2}{*}{ Compound } & \multicolumn{2}{|c|}{ Inhibition } \\
\hline & $\begin{array}{l}\text { ATPase activity } \\
I C_{50}\left(\mu \mathrm{mol} \mathrm{L}^{-1}\right)\end{array}$ & $\begin{array}{l}\text { Helicase activity } \\
I C_{50}\left(\mu \mathrm{mol} \mathrm{L}^{-1}\right)\end{array}$ \\
\hline 4-Amino-5-hydrazino-4H-1,2,4-triazole-3-thiol & 8.9 & 12.4 \\
\hline 4-Amino-5-(2-fluorophenyl hydrazine)-4H-1,2,4-triazole-3-thiol (1) & $>100$ & $>100$ \\
\hline 4-Amino-5-(4-fluorophenyl hydrazine)-4H-1,2,4-triazole-3-thiol (2) & $>100$ & $>100$ \\
\hline 4-Amino-5-(2-chlorophenyl hydrazine)-4H-1,2,4-triazole-3-thiol (3) & $>100$ & $>100$ \\
\hline 4-Amino-5-(4-chlorophenyl hydrazine)-4H-1,2,4-triazole-3-thiol (4) & 94.81 & $>100$ \\
\hline 4-Amino-5-(2-bromophenyl hydrazine)-4H-1,2,4-triazole-3-thiol (5) & $>100$ & $>100$ \\
\hline 4-Amino-5-(4-bromophenyl hydrazine)-4H-1,2,4-triazole-3-thiol (6) & $>100$ & $>100$ \\
\hline 4-Amino-5-(2-iodophenyl hydrazine)-4H-1,2,4-triazole-3-thiol (7) & $>100$ & $>100$ \\
\hline 4-Amino-5-(4-iodophenyl hydrazine)-4H-1,2,4-triazole-3-thiol (8) & 87.64 & $>100$ \\
\hline $\begin{array}{l}\text { 4-(Cyclopent-1-en-3-ylamino)-5-[2-(2-fluorophenyl) hydrazinyl]-4H- } \\
\text { 1,2,4-triazole-3-thiol (9) }\end{array}$ & $>100$ & $>100$ \\
\hline $\begin{array}{l}\text { 4-(Cyclopent-1-en-3-ylamino)-5-[2-(4-fluorophenyl) hydrazinyl]-4H- } \\
\text { 1,2,4-triazole-3-thiol (10) }\end{array}$ & 58 & $>100$ \\
\hline $\begin{array}{l}\text { 4-(Cyclopent-1-en-3-ylamino)-5-[2-(2-chlorophenyl) hydrazinyl]-4H- } \\
\text { 1,2,4-triazole-3-thiol (11) }\end{array}$ & 3.9 & 5.7 \\
\hline $\begin{array}{l}\text { 4-(Cyclopent-1-en-3-ylamino)-5-[2-(4-chlorophenyl) hydrazinyl]-4H- } \\
\text { 1,2,4-triazole-3-thiol (12) }\end{array}$ & 0.51 & 3.0 \\
\hline $\begin{array}{l}\text { 4-(Cyclopent-1-en-3-ylamino)-5-[2-(2-bromo-phenyl) hydrazinyl]-4H- } \\
\text { 1,2,4-triazole-3-thiol (13) }\end{array}$ & 5.3 & 9.0 \\
\hline $\begin{array}{l}\text { 4-(Cyclopent-1-en-3-ylamino)-5-[2-(4-bromo-phenyl) hydrazinyl]-4H- } \\
\text { 1,2,4-triazole-3-thiol (14) }\end{array}$ & 4.0 & 6.3 \\
\hline $\begin{array}{l}\text { 4-(Cyclopent-1-en-3-ylamino)-5-[2-(2-iodophenyl) hydrazinyl]-4H- } \\
\text { 1,2,4-triazole-3-thiol (15) }\end{array}$ & 2.73 & 4.3 \\
\hline $\begin{array}{l}\text { 4-(Cyclopent-1-en-3-ylamino)-5-[2-(4-iodophenyl) hydrazinyl]-4H- } \\
\text { 1,2,4-triazole-3-thiol (16) }\end{array}$ & 0.47 & 2.5 \\
\hline
\end{tabular}

\section{Structure-activity relationship (SAR)}

It is clear from the obtained results of the biological evaluation that, in general, the existence of cyclopentene in structure of compounds under assay is essential for activity. The para-substitution in 4-(cyclopent-1-en-3-ylamino)-5-[2-(halophenyl) hydrazinyl]-4H-1,2,4-triazole-3-thiols $\mathbf{9 - 1 6}$ is better for helicase inhibitory activity. Additionally, the inhibitory activity varies according to the halogen-type substitution. It was observed that the most potent derivative was that comprising iodine followed by chlorine and then bromine. The weakest activity, if any, was noticed with fluoro-derivatives. This comes in accordance with the previous studies reporting that iodo-derivatives exhibited the most potent activity 

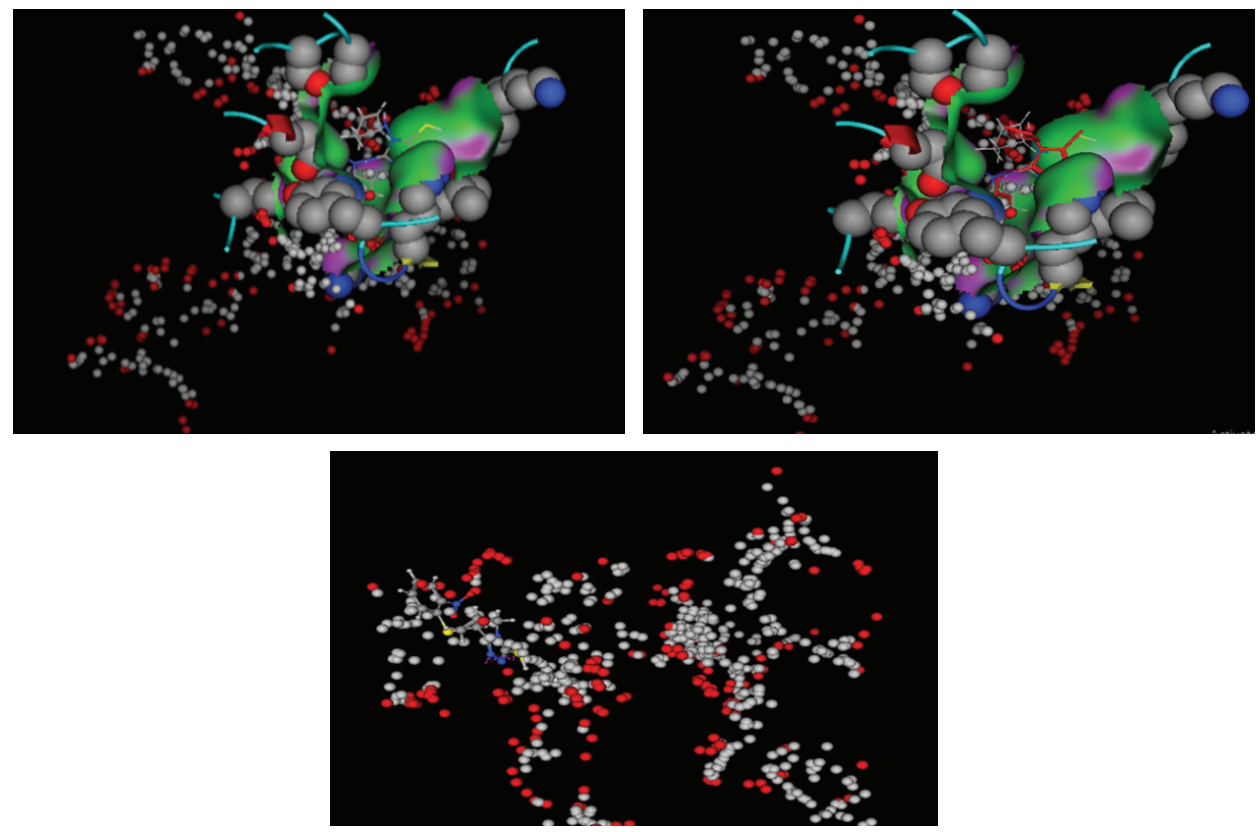

Fig. 4. a) 4-(Cyclopent-1-en-3-ylamino)-5-[2-(4-iodophenyl)hydrazinyl]-4H-1,2,4-triazole-3-thiol (16) docking into inhibitor binding pocket of MERS-CoV (5WWP), b) 4-(Cyclopent-1-en-3-ylamino)5-[2-(4-chlorophenyl)hydrazinyl]-4H-1,2,4-triazole-3-thiol (12) docking into binding pocket of MERS$\mathrm{CoV}$ (5WWP). c) SSYA-10 docking into inhibitor binding pocket of MERS-CoV (5WWP).

as helicase inhibitors against replication of coronaviruses (24). In addition, it was reported that the aromatic substituent influences dramatically te anti-corona viruses activity (25). The current study reveals that orientation of halogen affected the activity, so that para-substituted compounds within the series 9-16 were showed higher helicase inhibitory activity compared to the ortho-ones.

\section{CONCLUSIONS}

Sixteen new halogenated triazole derivatives were designed and synthesized. Structures of target compounds were justified via microanalytical and spectral data. Obtained compounds 1-16 were subjected to evaluation against MERS-CoV helicase. The most potent compounds were $p$-iododerivative, 4-(cyclopent-1-en-3-ylamino)-5-[2-(4-iodophenyl) hydrazinyl]-4H-1,2,4-triazole-3-thiol (16), and para-chloro derivative, 4-(cyclopent1-en-3-ylamino)-5-[2-(4-chlorophenyl)hydrazinyl]-4H-1,2,4-triazole-3-thiol (12). In silico, molecular docking was accomplished on the most potent compounds into the active binding site of MERS-CoV helicase nsp13, to support the experimental findings. Computational results harmonize well with the experimental ones.

Therefore, exploring new anti-MERS-CoV agents might lead to future drugs after full toxicological and preclinical investigations. 
N. H. Zaher et al.: Design, synthesis and molecular docking of novel triazole derivatives as potential CoV helicase inhibitors, Acta Pharm. 70 (2020) 145-159.

Acknowledgements. - Authors would like to express their gratitude to Egyptian Atomic Energy Authority (EAEA), National Center for Radiation Research and Technology (NCRRT), Drug Radiation Research Department, drug chemistry lab, for the accommodation of the chemical synthetic part of this work. Authors would like also to extend their sincere appreciation to the deanship of Scientific Research at King Faisal University for its funding of this research through the research Project no. 160002 .

Supplementary Material is available upon request.

\section{REFERENCES}

1. R. L. Graham, E. F. Donaldson and R. S. Baric, A decade after SARS: strategies for controlling emerging coronaviruses, Nat. Rev. Microbiol. 11 (2013) 836-848; https://doi.org/10.1038/nrmicro3143

2. V. S. Raj, H. Mou, S. L. Smits, D. H. Dekkers, M. A. Müller, R. Dijkman, D. Muth, J. A. Demmers, A. Zaki, R. A. Fouchier, V. Thiel, C. Drosten, P. J. Rottier, A. D. Osterhaus, B. J. Bosch and B. L. Haagmans, Dipeptidyl peptidase 4 is a functional receptor for the emerging human coronavirusEMC, Nature 495 (2013) 251-254; https://doi.org/10.1038/nature12005

3. A. M. Zaki, S. V. Boheemen, T. M. Bestebroer, A. D. Osterhaus and R. A. Fouchier, Isolation of a novel coronavirus from a man with pneumonia in Saudi Arabia, N. Engl. J. Med. 367 (2012) 18141820; https://doi.org/10.1056/NEJMoa1211721

4. P. A. Rota, M. S. Oberste, S. S. Monroe, W. A. Nix, R. Campagnoli, J. P. Icenogle, S. Peñaranda, B. Bankamp, K. Maher, M. H. Chen, S. Tong, A. Tamin, L. Lowe, M. Frace, J. L. DeRisi, Q. Chen, D. Wang, D. D. Erdman, T. C. Peret, C. Burns, T. G. Ksiazek, P. E. Rollin, A. Sanchez, S. Liffick, B. Holloway, J. Limor, K. McCaustland, M. Olsen-Rasmussen, R. Fouchier, S. Günther, A. D. Osterhaus, C. Drosten, M. A. Pallansch, L. J. Andersonthe and W. J. Bellini, Characterization of a novel coronavirus associated with severe acute respiratory syndrome, Science 300 (2003) 1394-1399; https://doi.org/10.1126/science.1085952

5. J. S. M. Peiris, K. Y. Yuen, A. D. M. E. Osterhaus and K. Stöhr, The severe acute respiratory syndrome, N. Engl. J. Med. 349 (2003) 2431-2441; https://doi.org/10.1056/NEJMra032498

6. P. M. Penttinen, K. Kaasik-Aaslav, A. Friaux, A. Donachie, B. Sudre, A. J. Amato-Gauci, Z. A. Memish and D. Coulombier, Taking stock of the first 133 MER S coronavirus cases globally - Is the epidemic changing? Euro Surveill. 18 (2013) 1-5; https://doi.org/10.2807/1560-7917.ES2013.18.39.20596

7. World Health Organization, MERS-CoV Global Summary and Assessment of Risk, (WHO/MERS/RA/ August18), WHO, Geneva 2018

8. A. O. Adedeji and S. G. Sarafianos, Antiviral drugs specific for coronaviruses in preclinical development, Curr. Opin. Virol. 8 (2014) 45-53; https://doi.org/10.1016/j.coviro.2014. 06.002

9. L. J. Stockman, R. Bellamy and P. Garner, SARS: Systematic review of treatment effects, PLoS Med. 3 (2006) 1525-1531; https://doi.org/10.1371/journal.pmed. 0030343

10. R. Y. Kao, W. H. Tsui, T. S. Lee, J. A. Tanner, R. M. Watt, J. D. Huang, L. Hu, G. Chen, Z. Chen, L. Zhang, T. He, K. H. Chan, H. Tse, A. P. To, L. W. Ng, B. C. Wong, H. W. Tsoi, D. Yang, D. D. Ho and K. Y. Yuen, Identification of novel small-molecule inhibitors of severe acute respiratory syndromeassociated coronavirus by chemical genetics, Chem. Biol. 11 (2004) 1293-1299; https://doi. org/10.1016/j. chembiol.2004.07.013

11. D. N. Frick and A. M. I. Lam, Understanding helicases as a means of virus control, Curr. Pharm. Des. 12 (2006) 1315-1338; https://doi.org/10.2174/138161206776361147

12. W. Hao, J. A. Wojdyla, R. Zhao, R. Han, R. Das, I. Zlatev, M. Manoharan, M. Wang and S. Cui, Crystal structure of Middle East respiratory syndrome coronavirus helicase, PLoS Pathog. 13 (2017) e1006474 (19 pages); https://doi.org/10.1371/j.ppat.1006474 
N. H. Zaher et al:: Design, synthesis and molecular docking of novel triazole derivatives as potential CoV helicase inhibitors, Acta Pharm. 70 (2020) 145-159.

13. A. O. Adedeji and H. Lazarus, Biochemical characterization of Middle East respiratory syndrome coronavirus helicase, mSphere 1 (2016) e00235-16 (14 pages); https://doi.org/org/10.1128/ mSphere.00235-16

14. D. Dheer, V. Singh and R. Shankar, Medicinal attributes of 1,2,3-triazoles: Current developments, Bioorg. Chem. 71 (2017) 30-54; https://doi.org/10.1016/j.bioorg.2017.01.010

15. Y. W. He, C. Z. Dong, J. Y. Zhao, L. Ma, Y. H. Li and H. A. Aisa, 1,2,3-Triazole-containing derivatives of rupestonic acid: Click-chemical synthesis and antiviral activities against influenza viruses, Eur. J. Med. Chem. 76 (2014) 245-255; https://doi.org/10.1016/j.ejmech. 2014.02.029

16. J. Zhao and H. A. Aisa, Synthesis and anti-influenza activity of aminoalkyl rupestonates, Bioorg. Med. Chem. Lett. 22 (2012) 2321-2325; https://doi.org/10.1016/j.bmcl.2012.01.056

17. A. O. Adedeji, K. Singh, N. E. Calcaterra, M. L. DeDiego, L. Enjuanes, S. Weiss and S. G. Sarafianos, Antimicrob. Agents Chemother. 56 (2012) 4718-4728; https://doi.org/10.1128/AAC.00957-12

18. A. O. Adedeji, K. Singh, A. Kassim, C. M. Coleman, R. Elliott, S. R. Weiss, M. B. Frieman and S. G. Sarafianos, Evaluation of SSYA10-001 as a replication inhibitor of SARS, MHV and MERS coronaviruses, Antimicrob. Agents Chemother. 58 (2014) 4894-898; https://doi.org/10.1128/AAC.02994-14

19. A. A. Fadda, S. Bondock, R. Rabie and H. A. Etman, Cyanoacetamide derivatives as synthons in heterocyclic synthesis, Turk. J. Chem. 32 (2008) 259-286; https://doi.org/10.1.1.574.4827

20. J. A. Tanner, R. M. Watt, Y. B. Chai, L. Y. Lu, M. C. Lin, J. S. Peiris, L. L. Poon, H. F. Kung and J. D. Huang, The severe acute respiratory syndrome (SARS) coronavirus NTPase/helicase belongs to a distinct class of 5' to 3' viral helicases, J. Biol. Chem. 278 (2003) 39578-39582; https://doi.org/10.1074/ jbc.C300328200

21. D. J. T. Porter, Inhibition of the hepatitis $C$ virus helicase-associated ATPase activity by the combination of ADP, NaF, $\mathrm{MgCl}_{2}$, and poly(rU) - Two ADP binding sites on the enzyme-nucleic acid complex, J. Biol. Chem. 273 (1998) 7390-7396; https://doi.org/10.1074/jbc.273.13.7390

22. A. M. Boguszewska-Chachulska, M. Krawczyk, A. Stankiewicz, A. Gozdek, A-L. Haenni and L. Strokovskaya, Direct fluorometric measurement of hepatitis C virus helicase activity, FEBS Lett. 567 (2004) 253-258; https://doi.org/10.1016/j.febslet.2004.04.072

23. M. K. Abdel-Hamid, A. A. Abdel-Hafez, N. A. El-Koussi, N. M. Mahfouz, A. Innocenti and C. T. Supuran, Design, synthesis, and docking studies of new 1,3,4-thiadiazole-2-thione derivatives with carbonic anhydrase inhibitory activity, Bioorg. Med. Chem. 15 (2007) 6975-6984; https://doi. org/10.1016/j.bmc.2007.07.044

24. J. A. Tanner, B. J. Zheng, J. Zhou, R. M. Watt, J. Q. Jiang, K. L. Wong, Y. P. Lin, L.Y. Lu, M. L. He, H. F. Kung, A. J. Kesel and J. D. Huang, The adamantane-derived bananins are potent inhibitors of the helicase activities and replication of SARS coronavirus, Chem. Biol. 12 (2005) 303-311; https:// doi.org/10.1016/j.chembiol.2005. 01.006

25. Z-Y. Wu, N. Liu, B. Qin, L. Huang, F. Yu, K. Qian, S. L. Morris-Natschke, S. Jiang, C. H. Chen, K-H. Lee and L. Xie, Optimization of the antiviral potency and lipophilicity of halogenated 2,6-diarylpyridinamines as a novel class of HIV-1 NNRTIS, ChemMedChem 9 (2014) 1546-1555; https://doi. org/10.1002/ cmdc.201400075 